\title{
Characterization of Chloroquine-Induced Autophagic Vacuoles Isolated from Rat Liver ${ }^{1}$
}

\author{
Robert H. Gray, Marcia Sokol, Roberta K. Brabec, and \\ Michael J. BRABeC \\ Department of Environmental and Industrial Health, The University of Michigan, \\ Ann Arbor, Michigan 48109
}

Received April 14, 1980, and in revised form August 5, 1980

\begin{abstract}
Studies have been undertaken to investigate the role of cellular autophagy in the accommodation of stress in a biological system. Chloroquine (Aralen hydrochloride), an antimalarial and anti-intlammatory drug, was used to induce autophagy in rat liver. A method is presented which uses differential and discontinuous sucrose gradient centrifugation for the preparation of autophagic vacuole-enriched fractions from rat liver. Ultrastructural studies of the autophagic vacuole fractions showed that the integrity of the autophagic vacuoles was maintained throughout the isolation procedure and that they were morphologically similar to those seen in situ. Assay of glucose-6-phosphatase, NADPH-DCIP reductase, and acid phosphatase confirm the presence of membranes derived from the endoplasmic reticulum, as well as lysosomes, in the autophagic vacuole fractions. The distribution of $\left[{ }^{14} \mathrm{C}\right]-$ chloroquine suggested a preferential binding of the drug to the autophagic vacuoles may have occurred. These results suggest that cellular autophagy may play an important role in the accommodation of chemically induced alterations in hepatocytes by preferentially sequestering chloroquine, as well as restoring cellular ultrastructure.
\end{abstract}

\section{INTRODUCTION}

Biochemical, histochemical, and electron microscopic investigations support the concept that cells in different functional and pathological states are capable of sequestering and degrading portions of their own cytoplasm. This process can be referred to as cellular autophagy, during which autophagic vacuoles (AV) or cytolysosomes are formed. Cellular autophagy occurs at a low frequency in normal cells (de Duve, 1969; Ericsson, 1969a; Holtzman, 1976). A relatively high incidence of cellular autophagy is frequently exhibited by cells of tissues undergoing regeneration (Becker and Lane, 1965), atrophy (Helminen, 1976), differentiation (Scharrer, 1966) or embryological development (Locke and Collins, 1965; Locke and McMahon, 1971). The appearance of autophagic vacuoles in tissues can be drastically increased following exposure of animals to diverse chemical, physical, and biological agents, such as: glucagon (Ashford and Porter, 1962; Arstila and Trump, 1968; Deter, 1971, 1975a, b), chloroquine (Abraham et al., 1968), mitotic inhibitors (Arstila et al., 1974; Hirsimaki $e t$ al., 1975), cyclic AMP (Hirsimaki et al., 1975; Shelburne and Trump, 1968), actinomycin D (Arstila and Trump, 1968; Kovacs, 1972; Shelburne et al., 1973), DDT (Gray et al., 1970), hypoxia (Abraham et al., 1967; Cole et al., 1971), and ionizing irradiation (Hendlee and Alders, 1968; Rene et al., 1971; Jordan et al., 1972).

Since autophagy appears to be a common subcellular response to a variety of unrelated agents or conditions, it could be a fundamental subcellular process necessary for cell maintenance and protection after exposure to either toxic materials or diseases. To understand the role that cellular autophagy may play in the

\footnotetext{
${ }^{1}$ Supported by Michigan Memorial Phoenix Project Grant 478 and the H. H. Rackham School of Graduate Studies Grant FRF-91.
} 
response to environmental stress, a more complete understanding of the origin and nature of the AV is required. As an initial step in this investigation, a method was developed for the isolation of AV from rat liver following their induction by chloroquine. Previous work has shown that maximum induction of AV occurs at 2 hr postdose (Wisner-Gebhart et al., 1979). Histochemical and biochemical assays were performed on the fractions to identify the contents of the vacuoles. The distribution of $\left[{ }^{14} \mathrm{C}\right]$ chloroquine in the various fractions was also determined. Preliminary reports of some of these data have been made (Brabec et al., 1979; Gray et al., 1973, 1974).

\section{METHODS AND MATERIALS}

Animals and drug doses. All experiments were carried out on male CFN strain albino rats (100 to $135 \mathrm{~g}$ ) from a randomly inbred colony maintained in this laboratory. Chloroquine (Aralen hydrochloride, Winthrop Laboratories, New York, N.Y.) was administered intraperitoneally at a dose of $40 \mathrm{mg} / \mathrm{kg}$ body wt. The animals were decapitated $2 \mathrm{hr}$ after the injection of the drug. A portion of the central lobe of the liver was removed and prepared for electron microscopy (see below) and the rest of the liver was used for fractionation and preparation of the AV.

$\left[{ }^{14} \mathrm{C}\right]$ Chloroquine studies. $\left[{ }^{14} \mathrm{C}\right]$ Chloroquine (New England Nuclear, Boston, Mass., specific activity $5 \mathrm{mCi} / \mathrm{mmole}$ ) was solubilized in absolute ethanol and 1 part was added to 4 parts "carrier" Aralen hydrochloride. The radioactive mixture was administered intraperitoneally at a dose of $40 \mathrm{mg} / \mathrm{kg} 2 \mathrm{hr}$ prior to sacrifice. Samples were removed from each step of the isolation procedure to determine the distribution of $\left[{ }^{14} \mathrm{C}\right]$ chloroquine. Sample aliquots $(0.1 \mathrm{ml})$ were digested in Protosol (New England Nuclear) according to the manufacturer's instructions, and the radioactivity was determined in a Packard Model 3375 scintillation spectrometer.

Electron microscopy. Whole liver samples approximately $0.5 \mathrm{~mm}^{3}$ were fixed in $3 \%$ glutaraldehyde $-0.1 M$ sodium phosphate buffer ( $\mathrm{pH} 7.2$ ), as described by Sibrack et al. (1974). Subcellular fractions from gradients were diluted with water to approximately $0.25 \mathrm{M}$ sucrose before being centrifuged at $17,000 \mathrm{~g}$ for $15 \mathrm{~min}$ at $4^{\circ} \mathrm{C}$. The resulting pellets were made very thin $(0.2$ to $0.5 \mathrm{~mm})$ to facilitate fixation, infiltration of Epon, and ultrastructural visualization of the entire pellet. Thin sections were made with a Reichert OmU-2 ultramicrotome using glass or diamond knives and placed on Formvar-carbon-coated grids. The sections were poststained with 6\% aqueous uranyl magnesium acetate and Reynold's lead citrate. Specimens were examined and photographed with an AEI Corinth 275 electron microscope at $60 \mathrm{kV}$.

Subcellular fractionation. Figure 1 outlines the procedures used for the fractionation and isolation of $\mathrm{AV}$ as adapted from Leighton et al. (1968). All operations were conducted at $0-4^{\circ} \mathrm{C}$. Livers from four to six animals were combined, minced, and washed in $0.25 \mathrm{M}$ sucrose followed by homogenization in $10 \mathrm{vol}$ of $0.25 M$ sucrose in a glass-Teflon homogenizer with three strokes of the pestle. The homogenate was centrifuged (Sorvall SS-34 rotor) for $10 \mathrm{~min}$ at $300 \mathrm{~g}_{\mathrm{av}}$ to remove whole cells and debris (Fraction P-1). The supernatant (S-1) was carefully decanted and centrifuged at $1085 g_{\text {av }}$ for 10 min to yield a "heavy mitochondria" pellet (P-2) and a supernatant, S-2. A "light mitochondria" pellet (P-3) was separated from the microsomes (S-3) by centrifugation of $\mathrm{S}-2$ for $3 \mathrm{~min}$ at $27,000 \mathrm{~g}_{\mathrm{av}}$. 


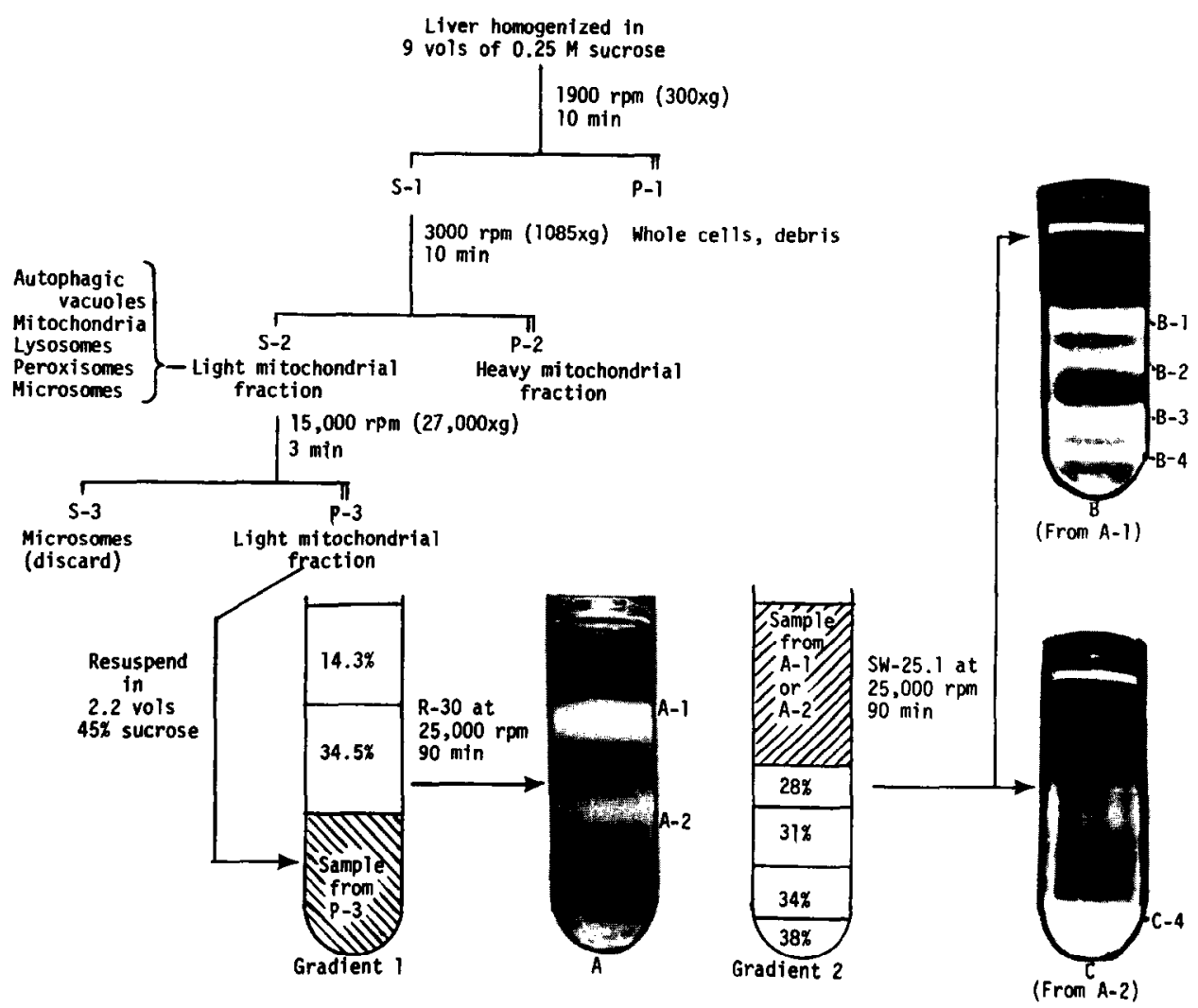

FIG. 1. Fractionation flow sheet.

P-3 was resuspended in $45 \%$ sucrose $(2.2 \mathrm{ml} / \mathrm{g}$ of combined liver weight). Fifteen milliliters of this suspension was placed at the bottom of a discontinuous gradient formed by layering $12 \mathrm{ml}$ of $34.5 \%$ and $10 \mathrm{ml}$ of $14.3 \%$ sucrose above the P-3 fraction. The gradients were centrifuged for $90 \mathrm{~min}$ at $25,000 \mathrm{rpm}\left(54,600 \mathrm{~g}_{\text {av }}\right)$ in a Spinco No. 30 rotor. The resulting gradient contained two bands, A-1 (upper) and $A-2$, at the interfaces of the sucrose layers. The upper and lower bands were removed through a 16-gauge needle and diluted with 2.5 and $4.0 \mathrm{vol}$ of distilled water, respectively, and $10 \mathrm{ml}$ of each was layered onto a second discontinuous gradient consisting of, in ascending order, $3 \mathrm{ml}$ of $38 \%, 5 \mathrm{ml}$ of $34 \%, 7 \mathrm{ml}$ of $31 \%$, and $5 \mathrm{ml}$ of $28 \%$ sucrose. These gradients were centrifuged in a Spinco SW 25.1 rotor at $25,000 \mathrm{rpm}\left(65,000 \mathrm{~g}_{\text {av }}\right)$ for $90 \mathrm{~min}$. The contents of the upper fraction, A-1, from the first gradient subfractionated into four bands in the second gradient, indicated as B-1, B-2, B-3, and B-4. Centrifugation of the second band, A-2, on the second discontinuous gradient yielded only a single band at the interface between the bottom two sucrose layers, and corresponded to the band B-4 (see Fig. 1) from A-1.

Enzyme assays. Glucose-6-phosphatase (G6Pase) activity was measured by the method of Nordlie and Arion (1966). Inorganic phosphate was determined as described by Ames (1966). The concentration of inorganic phosphate was calcu- 
lated on the basis that $0.01 \mu$ mole phosphate would yield an optical density of 0.26 at $820 \mathrm{~nm}$.

Acid phosphatase activity was determined as described by Barrett and Heath (1977), using 4-nitrophenyl phosphate as substrate. The concentration of product was calculated from a standard curve of absorbance at $420 \mathrm{~nm}$ over a range of 2-12 $\mu \mathrm{g} / \mathrm{ml}$ nitrophenol.

NADPH-DCIP reductase (NADPH: cytochrome $c$ reductase) activity was determined as described by Masters et al. (1966) by following the reduction of dichloroindolphenol (DCIP) at $600 \mathrm{~nm}$. Activity was calculated using $21 \times 10^{3} M^{-1}$ $\mathrm{cm}^{-1}$ as the extinction coefficient of reduced DCIP.

In all cases the assays were conducted under conditions in which the reaction was linear with respect to time and protein concentration.

Protein determinations. Protein was determined by the Lowry method (Lowry et al., 1951), and the Biuret reaction (Gornall et al., 1949). The 260-230 method of Kalf and Bernlohr (1977) was used to avoid the interference by high sucrose concentrations in the Lowry and Biuret methods. Bovine serum albumin was used as a reference solution for the Lowry and Biuret assays.

G6Pase localization in subcellular fractions. Subcellular fractions of AV were prepared by methods previously described above. The subcellular fractions from sucrose gradients were collected on Millipore filters rather than by centrifugation. Subcellular fractions were removed from the sucrose gradient, and diluted with water to a sucrose concentration of approximately $0.25 \mathrm{M}$. The sample was then placed in a 10-cc plastic syringe which was attached to a Swinny adapter containing a $0.45-\mu \mathrm{m}$ Millipore filter. Nitrogen (30-40 psi) was applied to the syringe forcing the sample onto the filter. Pressure was applied for about 30 min until the flow rate virtually ceased leaving a 10- to $30-\mu \mathrm{m}$ thick "wafer" of subcellular components on the filter. The filter was then removed from the Swinny adapter, cut into smaller pieces, and placed directly into the incubation medium (Leskes $e t$ al., 1971) for $1 \mathrm{hr}$ at $25^{\circ} \mathrm{C}$ in a shaking water bath. The cytochemical reaction was stopped by placing the filter containing samples into $2 \% \mathrm{OsO}_{4}-0.1 \mathrm{M}$ cacodylate buffer, $\mathrm{pH}$ 6.8, for $1 \mathrm{hr}$. Prior to dehydration, the filters were cut into small pieces and processed as indicated above for whole tissues. The Millipore filters were dissolved in the propylene oxide and the remaining thin "wafer" of subcellular components was embedded in Epon. The "wafer" was oriented perpendicularly to the long axis of the block face to facilitate visualization of the entire thickness of the "wafer" in each section. The sections were cut, mounted, and examined with and without poststaining.

Cytochemistry controls. A number of controls were run on the localization experiments to substantiate the assumption that the lead phosphate cytochemical reaction products visualized were actually from G6Pase. The controls included the following: (a) omission of the substrate (G6P) in the cytochemical medium, (b) omission of the capturing agent, $\mathrm{Pb}\left(\mathrm{NO}_{3}\right)_{2}$ from the cytochemical medium, and (c) heating of the tissue for $5 \mathrm{~min}$ to $80^{\circ} \mathrm{C}$ prior to incubation which inactivates G6Pase.

\section{RESULTS}

\section{Description of AV, in Situ}

The 2-hr exposure to chloroquine was selected because it produces the maximum number of autophagic vacuoles in rat hepatocytes (Wisner-Gebhart $e t$ 
al., 1979). The autophagic vacuoles contained cell components in various states of degradation (Fig. 2). With the exception of centrioles, lysosomes, Golgi apparatus, and nuclei, other subcellular components were observed within the AV.

\section{Isolation and Characterization of the AV Fractions}

Liver homogenate prepared from rats yielded a fraction enriched in AV (Fig. 1, P-3). This fraction contained about $25 \%$ of the protein, and about $40 \%$ of the glucose-6-phosphatase originally present in the homogenate (T'able 1). A lysosomal marker enzyme, acid phosphatase, partitioned primarily into the supernatant fraction (S-3), although 16-37\% of the enzyme remained in P-3 in the two trials in which this enzyme was measured. A microsomal enzyme, NADPH-DCIP reductase, remained primarily $(74 \%)$ in the supernatant. The specific activity of glucose-6-phosphatase and acid phosphatase was, within experimental error, the same in both fractions.

The resuspended P-3 was further fractionated into two discrete bands and a pellet, on a discontinuous sucrose gradient (Fig. 1). The upper band, A-1, contained primarily AV, lysosomes and membrane fragments, but few recognizable mitochondria or peroxisomes. A-1 contained $4 \%$ of the protein applied to the gradient. The specific activities of glucose-6-phosphatase, and acid phosphatase, were highest in the A-1 fraction, although the distribution of the two enzymes was not equal. About $7 \%$ of the glucose-6-phosphatase and $19-26 \%$ of acid phosphatase was in A-1. The bulk of the remaining enzyme activities was in the pellet (Table I). The lower band, A-2, contained membrane fragments, mitochondria, and occasional peroxisomes, but few AV. The specific activity and distribution of acid phosphatase indicated the presence of lysosomes in this fraction. Although
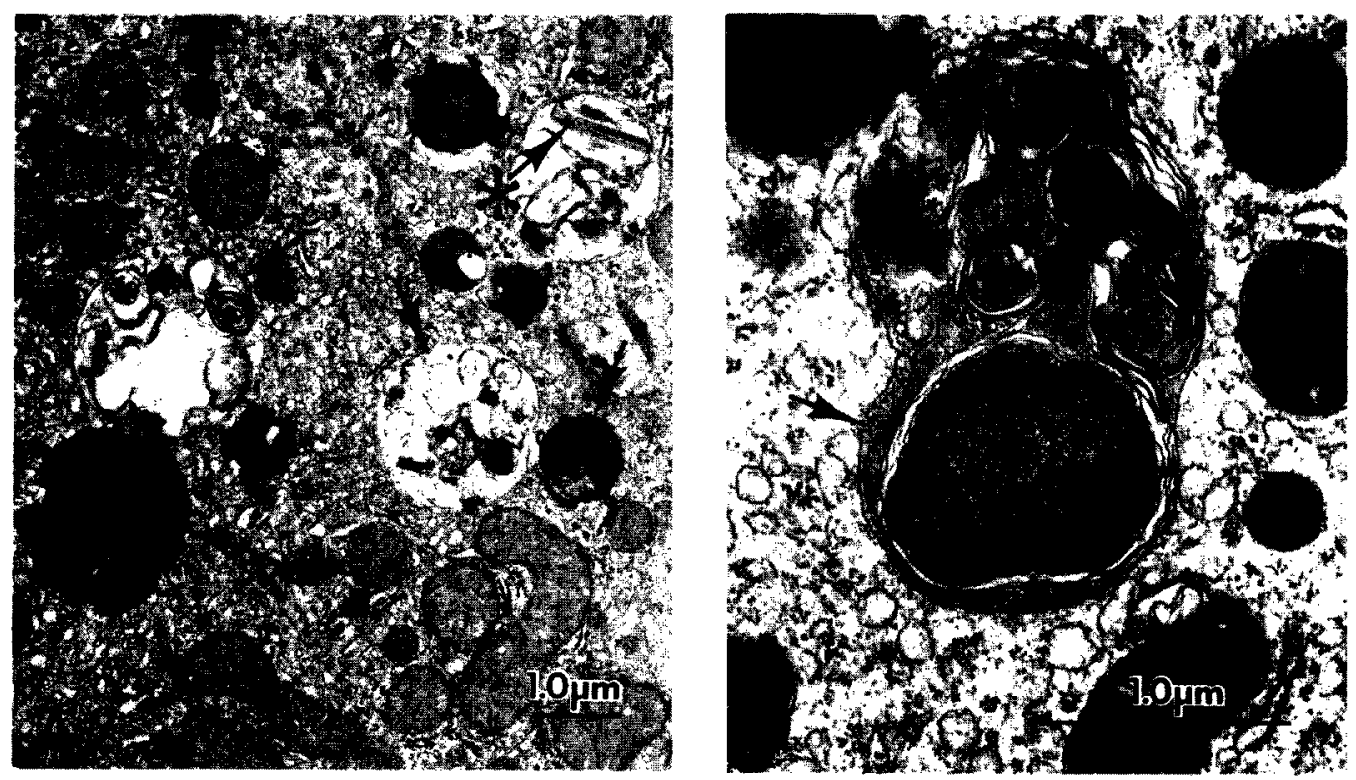

FIG. 2. Hepatocytes of chloroquine treated rats showing autophagic vacuoles (arrows). (A) Cytoplasm containing AV, one of which shows a crystaloid body of peroxisome $\left({ }^{*}\right) . \times 10,000$. (B) Liver cell showing sequestered and partially degraded organelles within the concentric layers of membranes of the AV. $\times 25,000$ 


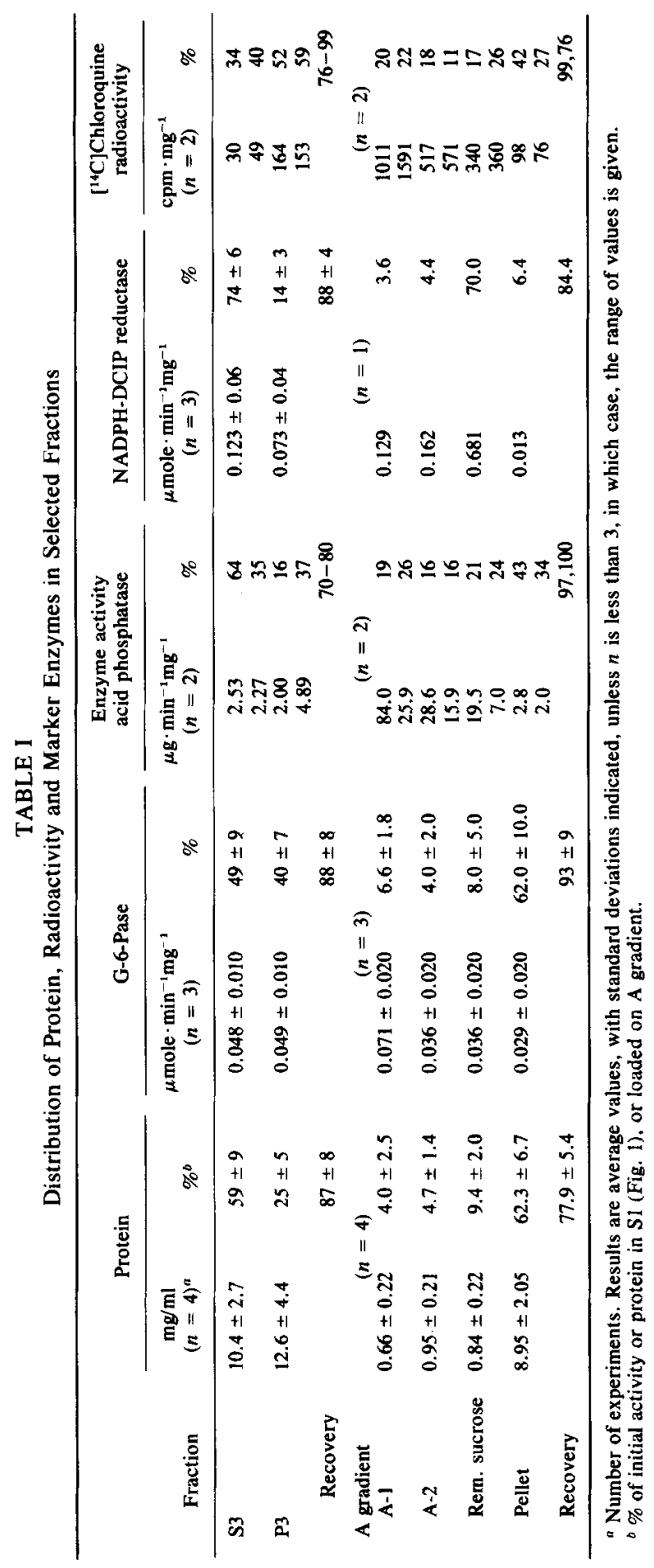


the specific activity of acid phosphatase varied considerably between two duplicate experiments, the relative distribution of the enzyme was the same. About $4 \%$ of the protein was found in A-2. The pellet contained $62 \%$ of the protein loaded on the gradient. NADPH-DCIP reductase was primarily found in the sucrose solution remaining after A-1, A-3, and the pellet were removed.

Further resolution of the A-1 fraction by the second discontinuous sucrose gradient centrifugation yielded four bands, B-1, B-2, B-3 and B-4. A typical field of the least dense fraction (B-1) consisted of osmiophilic lysosome-like dense bodies, AV, and membrane fragments (Fig. 3A). Fractions B-2 and B-3 consisted primarily of AV (Figs. 3B and C). The AV in the B-2 fraction (Fig. 3B) primarily appeared as a series of whorled membranes in which the inclusions were degraded and no longer recognizable. The AV in this fraction were more homogeneous in appearance than those of B-3 (Fig. 3C). These were considered to be AV in late stages of development. The contents of the AV from the B-3 fraction were more easily recognizable, and were quite heterogenous in structure. This fraction could be considered as AV in intermediate stages of development. The AV of B-3 fraction generally had a greater number of electron-dense components and fewer concentric lamellar membranes than those in B-2. Both the late and intermediate types of $\mathrm{AV}$ were seen in situ. The contents of the B-4 fraction were even more heterogeneous than B-3, and contained elcctron dense AV, frequently closely associated with membrane fragments, as well as mitochondria and some unidentifiable debris. The yield of the fourth band, B-4, was always less than the other bands of the gradient. The distribution of protein, glucose-6-phosphatase activity and acid phosphatase activity on the B-gradients is shown in Fig. 4. It can be seen that the enzyme activities were associated with the protein peaks, although acid phosphatase activity was greatest in the B-3 region, while glucose-6-phosphatase was enriched in the B-2 and B-1 region. NADPH-DCIP reductase activity (not shown) was very low and distributed uniformly down the gradient.

When fraction A-2 (Fig. 1) was run on the second gradient, only a single band, C-4 (Fig. 1), corresponding to B-4, was recovered. The contents of this band were similar to that of B-4.

The similarity of morphology of the AV in situ (Fig. 2) and in the subcellular fractions (Fig. 3) indicates that the chloroquine-induced organelles retained their structure throughout the isolation procedure.

\section{Controls: Nonchloroquine-Treated Animals}

Ultrastructural studies on control animals $(100-135 \mathrm{~g})$ rarely revealed hepatic autophagic vacuoles. It was observed that the frequency of $\mathrm{AV}$ increased in older animals, especially those weighing over $200 \mathrm{~g}$.

When livers of animals not receiving chloroquine were subjected to the isolation procedure, similar sucrose gradient patterns were obtained in the first discontinuous gradient, although the bands appeared smaller and less opaque. The presence of $\mathrm{AV}$ was rare in such fractions. When the upper fraction (A-1) was further resolved on the second sucrose gradient, the only visible fraction obtained corresponded to B-1 from the drug-treated animals. It contained primarily lysosomes and membrane fragments. No other bands were observed on the gradient which corresponded to the fractions B-2, B-3, and B-4 from the drug-treated animals.

\section{G6Pase in Enriched AV Subcellular Fractions $B-2$ and $B-3$}

The two fractions found to be most AV-rich, B-2 and B-3 of the second discon- 

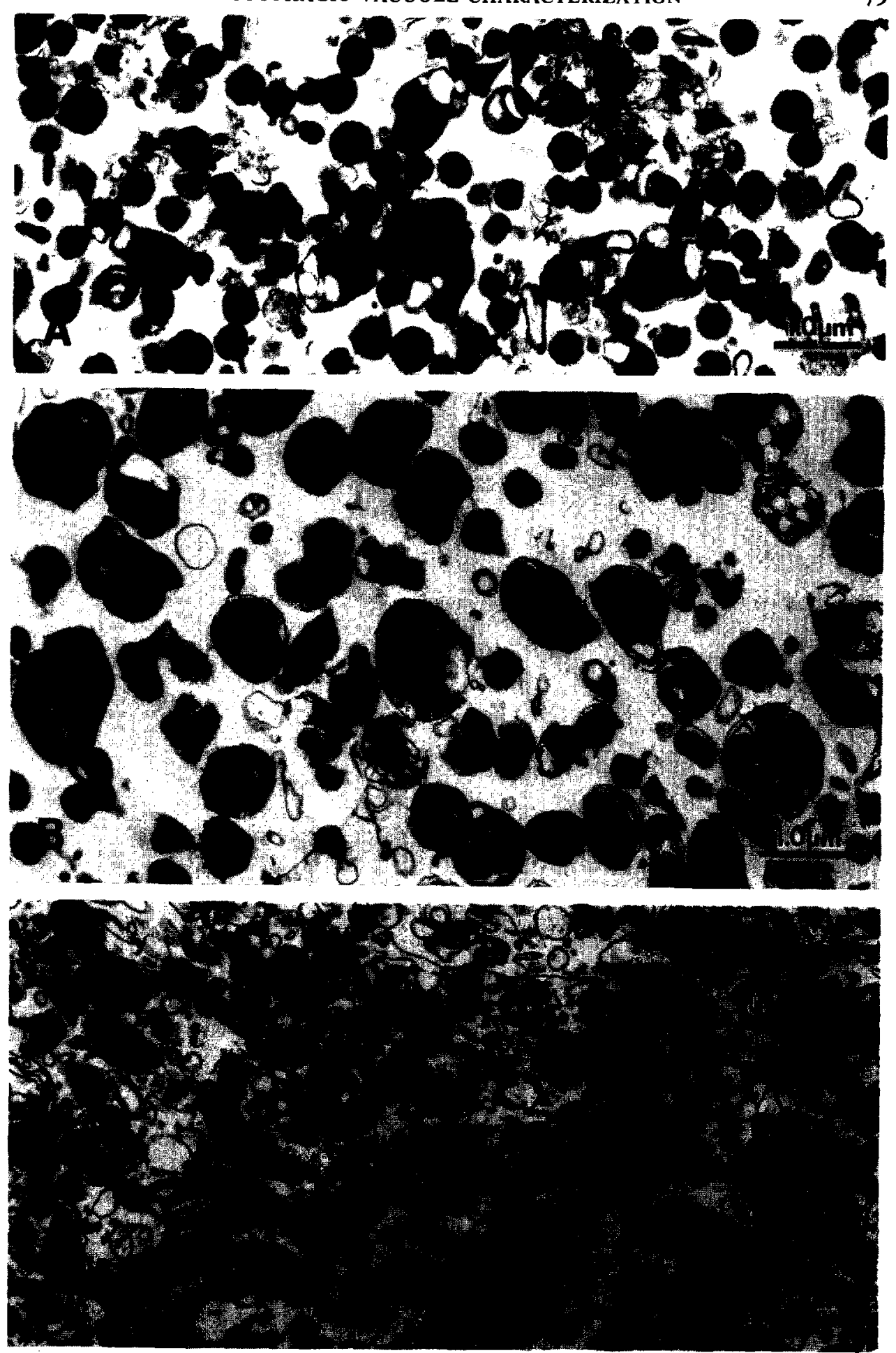

FIG. 3. Representative portions of B gradient fractions (Fig. 1, Tube B). (A) B-1 fraction: sample primarily composed of dense body-lysosome profiles with occasional AV and membrane fragments. $\times 12,000$. (B) B-2 fraction: the most enriched AV subcellular fraction with morphology similar to those seen in situ representing the late AV. $\times 12,000$. (C) Fraction B-3: contents similar to those in B-2 fraction but containing more electron dense areas within the AV representing the intermediate stage AV. $\times 12,000$. 

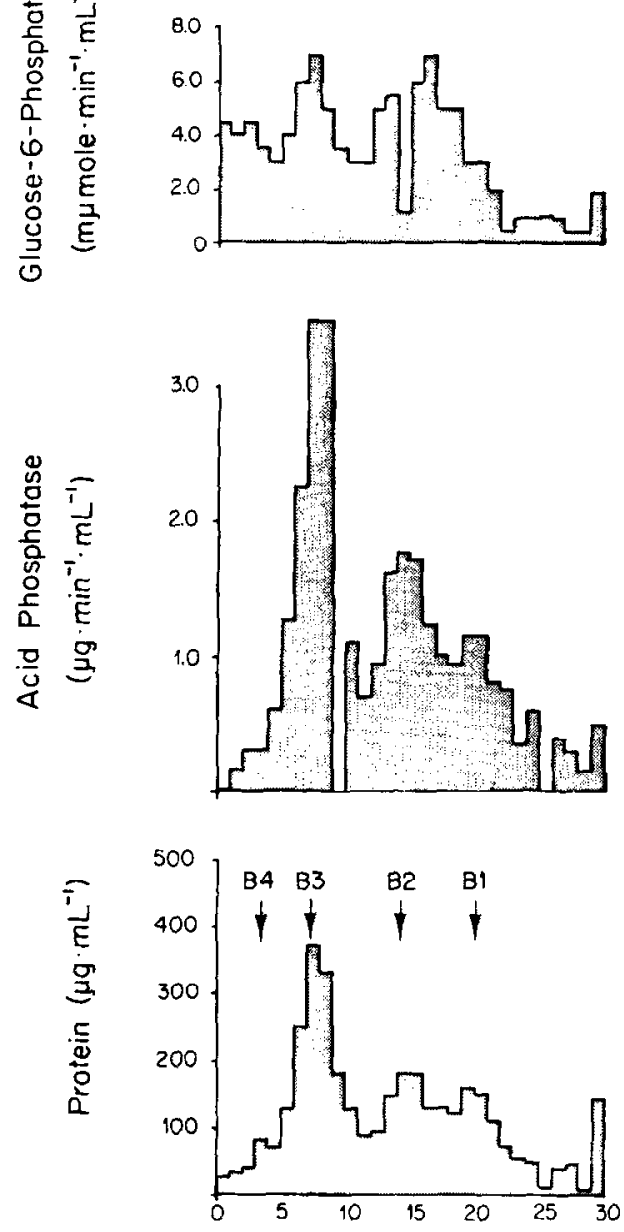

Fraction Number

FlG. 4. Distribution of protein, acid phosphatase, and glucose-6-phosphatase on fractions obtained from a typical B gradient. Thirty 1-ml fractions were collected by puncturing and draining the tube. Fraction 1 represents the bottom of the tube. Protein concentration and specific activity are expressed per ml of fraction. B-1, B-2, B-3, and B-4 labels refer to the fractions examined in Fig. 3.

tinuous sucrose gradient, were collected by filtration and examined cytochemically for the presence of G6Pase. Figure 5A shows isolated AV from the B-2 subcellular fraction; the fraction containing the highest yield and purity of "late AV." A cross section through the wafer containing the cytochemically reacted AV demonstrated electron dense reaction deposits throughout the sample (Fig. 5A). The lead phosphate deposits were generally seen associated with the outer portions of the isolated AV, although some deposits were found within the AV. The morphological configuration of the isolated AV after the cytochemical reaction was similar to that of untreated isolated $A V$.

The cytochemical labeling for G6Pase in the B-3 "intermediate AV" fraction (Fig. 5B) followed the same pattern as described for the B-2 fraction. The primary contaminants in this fraction were G6Pase-labeled membrane fragments which may be portions of the endoplasmic reticulum adhering to the isolated $\mathrm{AV}$. 

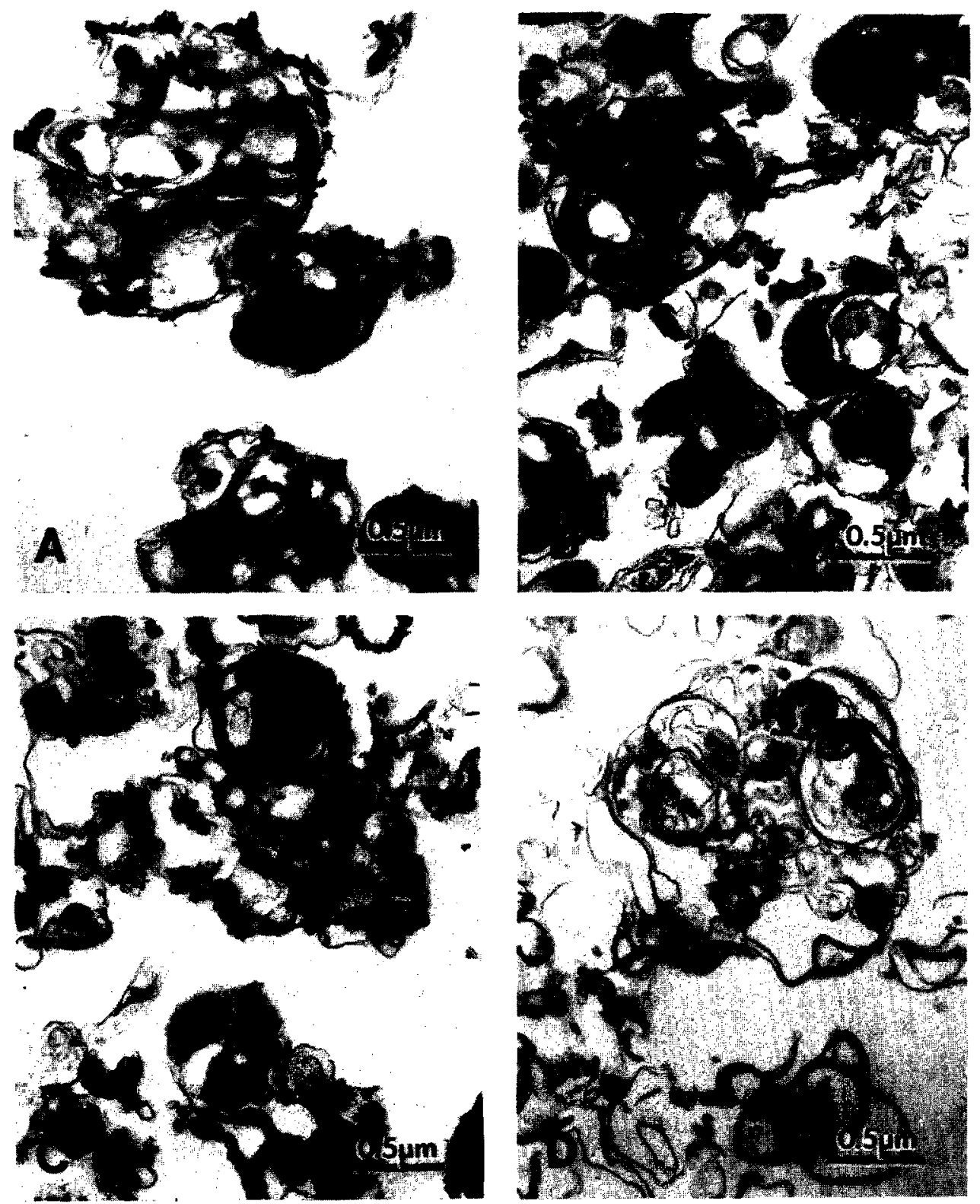

FIG. 5. G6Pase localization of AV-enriched subcellular fractions from the B gradient. (A) G6Pasepositive late AV from B-2 fraction. (B) G6Pase-positive intermediate AV from the B-3 of the sucrose gradient fraction. (C and D) G6Pase control on a fraction in which the substrate was omitted from the incubation medium. (Corresponds to $(A)$ and $(B)$, respectively). $\times 25,000$ each.

Typical cytochemical controls for the isolated AV fraction are shown in Figs. 5B and D. In the absence of the exogenous enzyme substrate, G6P, there was no detectable label in any part of the isolated AV or in any of the contaminating membranes. Likewise, the other cytochemical controls did not display any electron-dense deposits.

\section{$\left[{ }^{14} \mathrm{C}\right]$ Chloroquine Distribution in Subcellular Fractions}

The distribution of $\left[{ }^{14} \mathrm{C}\right]$ chloroquine in the subcellular fractions (Table I) shows 

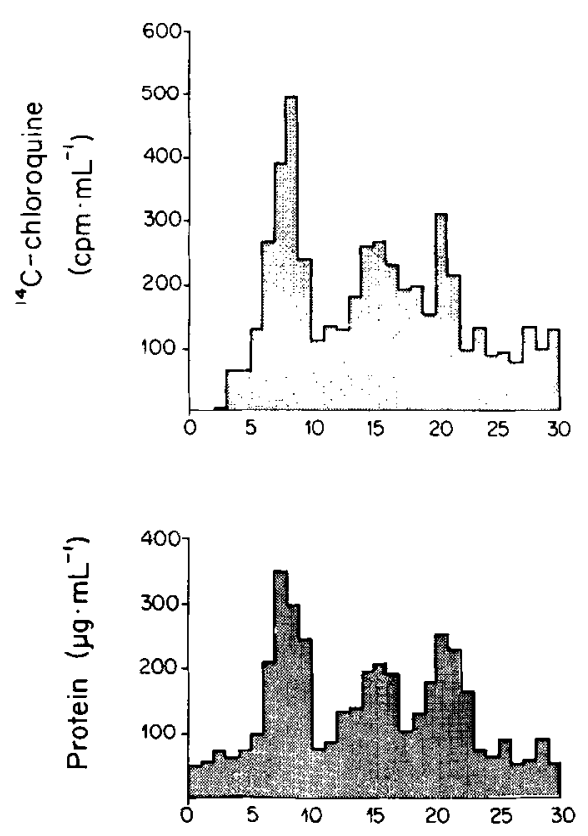

Fraction Number

F1G. 6. Distribution of protein and $\left[{ }^{14} \mathrm{C}\right]$ chloroquine on a typical $\mathrm{B}$ gradient. Experimental conditions were as Fig. 4. Radioactivity was measured as described in the text.

that the specific activity of the labeled drug was remarkably high in fraction A-1 of the first discontinuous sucrose gradient. The greatest increase in specific activity (7- to 10-fold) was achieved between the P-3 pellet, and the resolved A-1 fraction. About $22 \%$ of the ${ }^{14} \mathrm{C}$-labeled chloroquine was associated with $4 \%$ of the protein loaded on the gradient. The A-2 fraction was two- to threefold enriched and had less than $20 \%$ of the label. The gradient A pellet represented about $62 \%$ of the protein loaded on the gradient and had about $40 \%$ of the radioactivity. The distribution of radioactivity on the $B$ gradient revealed that $\left[{ }^{14} \mathrm{C}\right]$ chloroquine or a metabolite was associated with the major fractions on the B gradient (Fig. 6). The specific activity of the three fractions was about equal and similar to that of fraction A-1.

\section{DISCUSSION}

Autophagic vacuoles, purified on discontinuous sucrose density gradients, have been characterized with respect to ultrastructural and selected enzymatic properties. Two criteria were applied to evaluate the quality of the AV fractions. One, the appearance of the isolated AV should resemble that observed in situ, and second, the enzymatic properties should be consistent with those in situ.

Comparison of AV in situ (Fig. 2) with isolated AV [Figs. 3, 5 (fractions B-2 and B-3)] indicate that the criteria of morphological identity was fulfilled, and that considerable enrichment of AV was achieved in these fractions. Fractions B-2 and $B-3$ were designated as late and early $A V$, respectively, based on the morphological features of $A V$ in each fraction. Their differences are based on the progressive degradation of the sequestered components that occurred during the autophagic 
process. The presence of hydrolytic enzymes within the AV has been demonstrated cytochemically by Ericsson (1969b) and Arstila et al. (1972). It is reasonable to assume that the buoyant density of $\mathrm{AV}$ decreased as the autophagic process continued. The action of the hydrolytic enzymes would aid in degradation of high molecular weight components within the AV while the lipoproteins and lipids would be retained and be available to reassociate in the whorled myelin-like configurations seen in the late AV stages in the B-2 fraction (Fig. 3B). Therefore, the homogeneity of the AV types in the lighter fraction (B-2) and the heterogeneity of AV types in the heavier fraction (B-3) supports the argument that AV in earlier and later stages have been separated.

A second criteria for the quality of the preparation could be the relative distribution of glucose-6-phosphatase in the different subcellular fractions. Glucose6-phosphatase, a marker enzyme for the endoplasmic reticulum, was demonstrated to be associated with AV biochemically and ultrastructurally. Our results are in agreement with the in situ studies of Arstila and Trump (1968) regarding the localization of G6Pase in the early AV. Our studies also showed evidence for the presence of the enzyme in the more advanced or "late AV." Although the G6Pase reaction product was more prominent in the outer membrane, cytochemical reaction product was observed throughout the cross section of the isolated AV (Fig. 5). Such an observation could be interpreted to mean that the AV had sequestered endoplasmic reticulum membranes in addition to having endoplasmic reticulum membranes form the enveloping sheath around the AV. The distribution of acid phosphatase, a marker enzyme for lysosomes, also coincided with the AVcontaining fractions. While the B-1 fraction had lysosomal-like structures, less than expected acid phosphatase activity was found in this fraction. The presence of lysosomes in B-2 and B-3 was not apparent, and may suggest that the enzyme was now associated with the $\mathrm{AV}$, an association that would be consistent with the degradation activities proceeding within the AV, as discussed above.

The specific activity of $\left[{ }^{14} \mathrm{C}\right]$ chloroquine showed a parallel increase with the purification of the AV (Table I). A-1 had the highest specific radioactivity in the first discontinuous gradient; about 10 -fold greater than that of the sample loaded. The distribution of $\left[{ }^{14} \mathrm{C}\right]$ chloroquine in the fractions of the $\mathrm{B}$ gradients showed the presence of the drug in both AV fractions, B-2 and B-3, as well as in fraction B-1. The highest content of $\left[{ }^{14} \mathrm{C}\right]$ chloroquine was in bands B-2 and B-3 (Fig. 6), indicating a remarkable preferential association of chloroquine with the AV. The AV apparently sequestered those membranes to which a significant portion of the drug was bound. The affinity of the labeled drug for the lysosomal fraction is consistent with the results of others that report an association of chloroquine with lysosomes (Wibo and Pool, 1974; Fedorko et al., 1968).

The biogenesis of hepatic AV induced by a variety of agents has been reviewed by Ericsson (1969a) and more recently by Helminen (1976) and Holtzman (1976). Two possibilities other than the endoplasmic reticulum have been proposed for the origin of membranes of $\mathrm{AV}$, namely derivation by de novo synthesis and from membranes of the Golgi complex. De novo synthesis seems questionable because several inhibitors of protein synthesis such as cycloheximide (Arstila and Trump, 1968), actinomycin D and puromycin (Shelburne et al., 1973) do not prevent AV formation but rather induce their formation. Histochemical studies on liver (Arstila and Trump, 1968; Farquhar et al., 1974) indicate that the double membranes of early AV have enzymes normally associated with the endoplasmic reticulum, such 
as inosine diphosphatase (IDPase) and G6Pase. While IDPase may be found in components of the Golgi apparatus, it should be noted that G6Pase is not present. It would seem unlikely that the Golgi lamellae are a source of AV membranes in hepatocytes. Our studies demonstrated the localization of a tightly bound endoplasmic reticulum enzyme, G6Pase, to the early and late AV membranes in situ. Also, the enzyme can be localized in the outer membrane of the isolated early and late AV. Therefore, the endoplasmic reticulum should be considered as one origin of the outer membrane of AV. These studies represent the first cytochemical study on the localization of an endoplasmic reticulum enzyme associated with the AV-enriched subcellular fractions.

Many of the agents known to induce cellular autophagy do not have prolonged effects on the cells after removal of the agent. This observation leads to questions concerning the function of AV in terms of the cell's ability to recover from a chemical or physical stress. For example, do AV engulf or sequester the exogenous toxic agent (as our data suggested to be the case with chloroquine) and thereby protect the other components of the cell from exposure? Do AV selectively sequester and degrade organelles damaged by the stressing agent? Although definite answers to these questions are not possible now, some preliminary observations can be made.

Based on the morphological observations made in the current study and those reported by Abraham and Hendy (1970) there is no evidence to suggest that there is a selective sequestration of visibly damaged organelles although the sequestration of biochemically altered organelles cannot be ruled out. In the early phases of the autophagy induction process (less than $1 \mathrm{hr}$ ) many AV contain what appear to be morphologically normal organelles, although they may take on aberrant appearances as they undergo degradation within the confines of the AV.

This leaves open the possibility that a cell can selectively remove those membranes which have preferentially bound the drug. This action would prevent further disturbances in the cell elicited by a foreign chemical. In such a case, this complex series of events could be seen as the accomodation of cells to a stress, realizing the reversible and rapid nature of the response (Mitra et al., 1975). Since cellular autophagy is induced by such a variety of unrelated chemical, physical, and biological stress agents and conditions, and in numerous cell types, this process could play an important role for the maintenance of normal cell growth (Ericsson, 1969a). Furthermore, the selective concentration of chloroquine in the AV may serve as a protective mechanism for the cell by preventing further interaction between the drug and other cell components. The relatively high content of the drug associated with the autophagic vacuole fraction suggests that the function of the autophagic process represents a mechanism of accommodation to stress.

\section{ACKNOWLEDGMENTS}

The authors wish to gratefully acknowledge the assistance of Ms. Patricia Daily and Mr. Stafford Cox in early phases of the work. We also wish to thank Dr. I. A. Bernstein and Dr. Tahir Rizki for their many helpful suggestions in the preparation of the manuscript.

\section{REFERENCES}

Abraham, R., Golberg, L., and Grasso, P. (1967). Hepatic response to lysosomal effects of hypoxia, neutral red and chloroquine. Nature (London) 215, 194-196. 
Abraham, R., and Hendy, R. (1970). Effects of chronic chloroquine treatment on lysosomes of rat liver cells. Exp. Mol. Pathol. 12, 148-159.

Abraham, R., Hendy, R., and Grasso, P. (1968). Formation of myeloid bodies in rat liver lysosomes after chloroquine administration. Exp. Mol. Pathol. 12, 148-159.

AMEs, B. N. (1966). Assay of inorganic phosphate, total phosphate and phosphatases. In "Methods in Enzymology" (E. F. Neufeld and V. Ginsburg, eds.), Vol. VIII, pp. 115-118. Academic Press, New York.

Arstila, A. U., Nuujn, I. J. M., and Trump, B. F. (1974). Studies on autophagocytosis. Vinblastine-induced autophagy in the rat liver. Exp. Cell Res. 87, 249-252.

Arstila, A. U., Shelburne, J. D., and Trump, B. F. (1972). Studies on autophagocytosis. A histochemical study on sequential alterations of mitochondria in the glucagon-induced autophagic vacuoles of rat liver. Lab. Invest. 27, 317-323.

Arstila, A. U., and Trump, B. F. (1968). Studies on cellular autophagocytosis. The formation of autophagic vacuoles in the liver after glucagon administration. Amer. J. Pathol. 53, 687-733.

Ashford, T. P., and PorTer, K. R. (1962). Cytoplasmic compounds in hepatic cell lysosomes. J. Cell Biol. 12, 198-202.

Barrett, A. J., and Heath, M. F. (1977). Lysosomal enzymes. In "Lysosomes, a Laboratory Handbook" (J. T. Dingle, ed.), 2nd ed., pp. 112-115. North-Holland, Amsterdam.

BECKER, F. F., and LANE, B. P. (1965). Regeneration of the mammalian liver. I. Autophagocytosis during differentiation of the liver cell in preparation for cell division. Amer. J. Pathol. 47, 783-801.

Brabec, M. J., Brabec, R. K., and GraY, R. H. (1979). Ultrastructural and biochemical studies on subcellular fractions of chloroquine induced autophagic vacuoles. Micron 10, 31-32.

Cole, S., Metter, A., and Karnovsky, M. J. (1971). Autophagic vacuoles in experimental atrophy. Exp. Mol. Pathol. 14(2), 158-175.

DETER, R. L. (1971). Quantitative characterization of dense body, autophagic vacuole, and acid phosphatase-bearing particle populations during the early phases of glucagon-induced autophagy in rat liver. J. Cell Biol. 48, $473-489$.

DETER, R. L. (1975a). Analog modeling of glucagon-induced autophagy in rat liver. I. Conceptual and mathematical model of telolysosme-autophagasome-autolysosome interaction. Exp. Cell Res. 94, 122-126.

DETER, R. L. (1975b). Analog modeling of glucagon-induced autophagy in rat liver. II. Evaluation of iron labeling as a means for identifying telolysosome, autophagosome and autolysosome populations. Exp. Cell Res. 94, 127-139.

DE DuVe, C. (1969). The lysosome in retrospect. In "Lysosomes in Biology and Pathology" (J. T. Dingle and H. B. Fell, eds.), Vol. 1, pp. 3-40. American Elsevier, New York.

Ericsson, J. L. E. (1969a). Mechanisms of cellular autophagy. In "Lysosomes in Biology and Pathology" (J. T. Dingle and H. B. Fell, eds.), Vol. 2, pp. 345-394. American Elsevier, New York.

Ericsson, J. L. E. (1969b). Studies on induced cellular autophagy. II. Characterization of the membrane bordering autophagosomes in parenchymal liver cells. Exp. Cell Res. 56, 393-405.

Farquhar, M. S., Bergeron, J. J. M., Siekevitz, P., and Palade, G. E. (1973). Cytochemistry of Golgi fractions prepared from rat liver. J. Cell Biol. 60, 8-25.

Fedorko, M. E., Hirsch, J., and Cohn, Z. A. (1968). Autophagic vacuoles produced in vitro. II. Studies on the mechanism of formation of autophagic vacuoles produced by chloroquine. $J$. Cell Biol. 38, 392-402.

Gray, R. H., Brabec, R. K., Foster, P. W., Cox, S., and Bernstein, I. A. (1974). The ultrastructural localization of glucose-6-phosphatase and the possible origin of concentric membranes of hepatic autophagic vacuoles. J. Cell Biol. 63, 240a.

Gray, R. H., Dailey, P., Brabec, M. J., Brabec, R. K., and Berkowitz, L. (1973). Isolation and ultrastructural characterization of autophagic vacuoles from hepatocytes of chloroquine-treated rats. J. Cell Biol. 59, 121a.

Gray, R. H., Dinman, B. D., and Bernstein, I. A. (1970). Ultrastructural abnormalities in rat liver after exposure to DDT. J. Cell Biol. 47, 78a.

Gornall, A. G., Bardawill, C. J., and David, M. M. (1949). Determination of serum proteins by means of the biuret reaction. J. Biol. Chem. 177, 751-766.

Helminen, H. J. (1976). The cellular mechanisms of hormonally induced tissue atrophy. In "Pathobiology of Cell Membranes" (B. F. Trump and A. U. Arstila, eds.), Vol. I, pp. 283-322. Academic Press, New York.

HendeE, W. R., and Alders, M. A. (1968). Ultrastructural development of radiation injury in hepatic parenchymal cells of $\gamma$-irradiated mice. Lab. Invest. 18(2), $151-158$. 
Hirsimaki, Y., Arstila, A. U., and Trump, B. F. (1975). Autophagocytosis: In vitro induction by microtubule poisons. Exp. Cell Res. 92, 11-14.

Holtzman, E. (1976). "Lysosomes: A survey." Springer-Verlag, New York.

Jordan, S. W., DeAn, P. N., and Alquist, J. (1972). Early ultrastructural effects of ionizing radiation. Lab. Invest. 27(2), 538-549.

KALF, V. F., and BERNLOHR, R. W. (1977). A new spectrophotometric assay for protein in cell extracts. Anal. Biochem. 82, 362-367.

KovaCs, J. (1972). Induced cellular autophagy in the epithelial cells of seminal vesicles of mice treated with actinomycin D. Acta Biol. Acad. Sci. Hung. 23(2), 181-193.

Leighton, F., Poole, B., Beaufay, H., Baudhain, P., Coffey, J. W., Flower, S., and de Duve, C. (1968). The large-scale separation of peroxisomes, mitochondria, and lysosomes from the livers of rats injected with Triton WR-1339. J. Cell Biol. 37, 482-513.

Leskes, A., Siekevitz, P., and Palade, G. E. (1971). Differentiation of endoplasmic reticulum in hepatocytes. II. Glucose-6-phosphatase in rough microsomes. $J$. Cell Biol. 49, 288-302.

Locke, M., and Collins, J. V. (1965). The structure and formation of protein granules in the fat body of the insect. J. Cell Biol. 26, 857-884.

Locke, M., and McMahon, J. T. (1971). The origin and fate of microbodies in the fat body of an insect. $J$. Cell Biol. 48, 61-78.

Lowry, O. H., Rosebrough, N. J., Farr, A. L., and Randall, R. J. (1951). Protein measurement with the Folin phenol reagent. J. Biol. Chem. 193, 265-275.

Masters, B. S., Williams, C. H., and Kamin, H. (1966). The preparation and propertics of microsomal TPNH-Cytochrome $c$ reductase from pig liver. In "Methods in Enzymology" (R. W. Estabrook and M. E. Pullman, eds.), Vol. X, pp. 565-566. Academic Press, New York.

Mitra, R. S., Gray, R. H., Cirin, B., and Bernstein, I. A. (1975). Molccular mechanisms of accommodation in Escherichia coli to toxic levels of $\mathrm{Cd}^{2+}$. J. Bacteriol. 121, 1180-1188.

Nordlie, R. C., and Arion, W. J. (1966). Glucose-6-phosphatase. In "Methods in Enzymology" (W. A. Wood, ed.), Vol. IX, pp. 619-623. Academic Press, New York.

Rene, A. A., Darden, J. A., and Parker, J. L. (1971). Radiation-induced ultrastructural and biochemical changes in lysosomes. Lab. Invest. 25(3), 230-239.

SCHARRER, B. (1966). Ultrastructural study of the regressing prothoracic glands of blattarian insects. Z. Zellforsch. Mikroskop Anat. 69, 1-21.

Shelburne, J. D., Arstila, A. U., and Trump, B. F. (1973). Studies on cellular autophagocytosis. Amer. J. Pathol. 73(3), 641-662.

Shelburne, J. D., and Trump, B. F. (1968). Inhibition of protein synthesis in flounder kidney tubules. Fed. Proc. 27, 410.

Sibrack, L. A., Gray, R. H., and Bfrnstfin, I. A. (1974). Localization of the histidine-rich protein in keratohyalin: Morphologic and macromolecular marker in epidermal differentiation. J. Invest. Derm. 62, 394-405.

WiBo, M., and PooL, B. (1974). Protein degradation in cultured cells. II. The uptake of chloroquine by rat fibroblasts and the inhibition of cellular protein degradation and cathepsin $\mathrm{B}_{1} . J$. Cell Biol. 63 , $430-440$.

Wisner-Gebhart, A. M., Brabec, R. K., and Gray, R. H. Morphometric studies of chloroquine induced autophagy in rat liver. Micron 10, 65-66. 